\title{
Multiperiod ordering model with put option contracts under inflation
}

\author{
Nana Wan ${ }^{* 1, a}, \operatorname{Li~Li}^{1, b}$ \\ ${ }^{1}$ School of Economics and Management, Southwest University of Science and Technology, Mianyang, China
}

\begin{abstract}
This paper considers the rising price and the shrinking demand caused by the inflation. To manage these above risks, the firm has a chance to place two types of orders in each period, viz., the firm order and the put options order. This paper formulates a multiperiod ordering model, either without or with put option contracts. Based on stochastic dynamic programming, this paper studies the optimal ordering policy structure in each period and provides an approximation to evaluate the corresponding policy parameters. By taking the case without put option contracts as a benchmark, put option contracts are demonstrated to prompt the firm to enhance the service level and improve the performance.
\end{abstract}

\section{Introduction}

If you often visit supermarkets to do some shopping, you can easily observe that the price levels of fruits, vegetable and meat have been going up at a fast pace. Although the price levels of toothpastes, cosmetics and laundry detergent remain the same as they did a few years ago, these goods have had their packages reduced in size so as to hide the increase in the price level. According to the World Bank, the global consumer price index raises at an average rate of $4.82 \%$ between 2008 and 2012. The major cause of the soaring price is attributed to inflation caused by the 2008 financial crisis. As a matter of fact, inflation has stayed above the $2 \%$ target for the extended periods following the crisis. As the inflation rate continues to increase, the prices always rise much faster than wages and that is not likely to change any time soon. People must afford more money to buy the same goods and so almost everyone has to tighten his belt in fear of what could lie ahead. For this reason, the consumer confidence hits rock bottom and thus the market demand becomes sluggish under inflation. Many firms are trapped in a dilemma under inflation. The real economy has a weak performance under inflation.

To accommodate the rapidly changing market, more and more firms start to adopt option contracts to manage various types of uncertainties, including yield, demand and price. For example, option contracts are used by Hewlett-Packard to purchase memory chips, scanner assemblies and so on [1]. Option contracts are attractive to the firm, who can ensure the supply and the pricing to meet uncertain demand. We do believe that option contracts are effective in hedging against the risks of price and demand caused by inflation. On the other hand, there are two types of unilateral options contracts: call ones and put ones. Call option contracts enable the firm to gain the right to reorder additional items while put option contracts enable the firm to gain the right to refund redundant items. We have discussed the case with call option contracts under inflation in Wan and Chen [2]. In this paper, we mainly focus on put option contracts. Two important questions are addressed in this paper:

- With and without put option contracts, what is the firm's optimal ordering policy in each period under inflation?

- What effect do put option contracts have on the firm under inflation?

We organize the rest part of this paper as follows. A brief literature review is given in section 2. Model description and assumptions are provided in section 3 . The firm's multiperiod ordering policies without and with put option contracts are analyzed in section 4 and 5, respectively. The impact of put option contracts on the firm's decisions and performance are discussed in section 6 . The numerical analysis is provided in section 7. Our conclusions are presented in section 8 .

\section{Literature review}

The first related research area mainly focuses on the firm's ordering or inventory decision under inflation. Tripathi et al. [3] derive the optimal solutions for the quantity, the time and the cost for a deteriorating item inventory under inflation, in which the demand is time dependent and the delay payment is related with the order quantity. Khurana [4] develops an inventory management model for deteriorating items with two warehouses and time-dependent demand under inflation. Das et al. [5] consider a multi-item multi-warehouse inventory model for deteriorating items with payment delay under inflation, in which demand is stock and price dependent. Bhunia et al. [6] build a two-warehouse 
inventory model with time dependent demand and different deterioration rates under inflationary conditions. All of these papers just concentrate the inventory control problem of a single firm under inflation. None of them involve put option contracts.

The second related research area mainly focuses on supply chain management with put option contracts. Xue et al. [7] study the optimal order quantity for the products and the optimal strike quantity for a risk-averse newsvendor with put option contract under CVaR downside risk measure. Wang and Chen [8] consider the joint ordering and pricing problem for a fresh produce firm with put option contract, in which where the demand is price sensitive and the circulation loss of fresh produce is considered. Basu et al. [9] compare put option contract to buyback contract within a supply chain with a risk-neutral supplier and a risk-averse retailer. Wan and Chen [10] discuss the impact of put option contract on a single-period supply chain under inflation. Hu et al. [11] prove the superiority of put option contract over both wholesale price contract and buyback contract on a relief supply chain with a supplier and a government. All of these papers just concentrate on the single-period problem.

The last related research area mainly focuses on the firm's multiperiod ordering problem. Lu et al. [12] adopt $\mathrm{K}$-approximate convexity to explore the multiperiod joint pricing and inventory problem with incomplete demand information and a non-concave revenue function. Feinberg and Liang [13] study the optimal ordering policies for a multi-period inventory control system with fixed ordering costs and all possible values of discount factor. Song et al. [14] develop a multiperiod optimization model that incorporates the reference price and the customer loss aversion to investigate the optimal inventory level, replenishment quantity and the corresponding price for a finite horizon inventory control system. Benjaafar et al. [15] explore the optimal policies for a multiperiod inventory control system with concave ordering costs. All of these papers never involve put option contracts and the effect of inflation.

\section{Model Description and assumptions}

This paper studies the multiperiod ordering problem for one firm under inflation. The firm buys one type of products from the supplier and sells them to the end customers in an inflation-affected market characterized by the rising price and the shrinking demand. The inventory of the firm is operated at time points $0, t, \ldots, n t$, in which the periodic time $t$ is a random viable over $(0, \tau)$ with cumulative distribution function $G_{i}(\cdot)$ and probability density function $g_{i}(\cdot)$. The whole selling cycle is divided into $n$ periods. Period $i$ is the time interval from the time point $(i-1) t$ to the time point it .

Owing to the effect of inflation, the retail price and the market demand vary in two directions in each period. Similar to Jaggi and Khanna [16], we assume that the retail price in period $i$, denoted as $P_{i}$, has a continuous exponential growth, i.e., $P_{i}=p_{i} e^{\gamma t}$, where $p_{i}$ is the initial retail price in period $i$ and $\gamma$ is the inflation rate over the whole selling cycle. Similar to Xiao et al. [17], we assume that the market demand in period $i$, denoted as $d_{i}\left(t, \varepsilon_{i}\right)$, is consisted of a deterministic form $x_{i}(t)$ and a stochastic error $\varepsilon_{i}$, i.e., $d_{i}\left(t, \varepsilon_{i}\right)=x_{i}(t)+\varepsilon_{i}$, where $x_{i}(t)$ is a declining function of periodic time $t$ and $\varepsilon_{i}$ is a random variable over $(0,+\infty)$ with invertible cumulative distribution function $F_{i}(\cdot)$ and probability density function $f_{i}(\cdot) . F_{i}(0)=0$ and $\bar{F}_{i}(\cdot)=1-F_{i}(\cdot)$ is the tail distribution.

Before the beginning of period $i$, the firm has a chance to place a firm order, denoted as $Q_{i}^{1}$, at unit wholesale price $w_{i}$ and purchase a certain quantity of put options, denoted as $q_{i}^{1}$, at unit option price $o_{i}$. If the firm places two types of orders, the firm can raise his inventory level up to $z_{i}^{1}$ by receiving the firm order $Q_{i}^{1}=z_{i}^{1}-y_{i}^{1}$ and can exercise the put options at unit exercise price $e_{i}$ to return the extra items if necessary. If the firm never places two types of orders, only the unsold items in the previous period are allowed to use to meet the market demand in that period. At the end of period $i$, the unsold items are carried in the inventory at unit holding cost $h_{i}$ to meet the market demand in the next period. At the end of the last period, unsold items can be salvaged at unit salvage value $v$. The discount factor is $\alpha$.

To avoid trivialities, we make the following assumptions: (1) The market is perfectly competitive and all the prices are exogenous. (2) The production lead-time of the firm order is negligible. (3) The firm cannot replenish his inventory during each period. (4) $h_{i}<\alpha h_{i+1}, \quad o_{i}<\alpha o_{i+1}, \quad e_{i}<\alpha e_{i+1}, \quad w_{i}<\alpha w_{i+1} \quad$ and $p_{i}<\alpha p_{i+1}$. These conditions ensure that unit holding cost, unit purchase and exercise price of put option, unit wholesale price and unit initial retail price are higher in the latter period than in the previous period. (5) $x_{i}(t)>x_{i+1}(t)$. This condition ensures that the market demand is higher than in the previous period than in the next period under inflation. (6) $w_{i}>e_{i}-o_{i}$, $h_{i}+w_{i}>\alpha w_{i+1}$ and $h_{n}+w_{n}>\alpha v$. The first condition ensures that the firm has a motivation to place the put options order in each period. The second condition ensures that the firm has no motivation to order more products than necessary in the previous period in order to meet the market demand in the next period. The third condition ensures the firm has no motivation to order infinite products than necessary in the last period in order to obtain the terminal value.

\section{Optimal ordering polices without put option contracts}


This section studies the firm's optimal ordering policies without put option contracts under inflation. We use the case without put option contract as a benchmark to compare with the case with put option contracts. Before the beginning of period $i$, the firm has a opportunity to place a firm order, denoted as $Q_{i}^{0}$. If the firm order is placed, the inventory level of the firm can be raised from $y_{i}^{0}$ to $z_{i}^{0}$. If the firm order is not placed, the inventory level of the firm can be still remained at $y_{i}^{0}$.

Let $V_{i}^{0}\left(y_{i}^{0}\right)$ be the profit-to-go function without put option contracts from period $i$ to period $n$. We develop the dynamic formulation as following:

$$
V_{i}^{0}\left(y_{i}^{0}\right)=w_{i} y_{i}^{0}+\max _{z_{i}^{0} \geq y_{i}^{0}}\left\{J_{i}^{0}\left(z_{i}^{0}\right)\right\}
$$

where $V_{n+1}^{0}\left(y_{i}^{0}\right)=v y_{i}^{0} \quad\left(y_{i}^{0} \geq 0\right)$, and

$$
\begin{aligned}
& J_{i}^{0}\left(z_{i}^{0}\right)=H_{i}^{0}\left(z_{i}^{0}\right)+\alpha V_{i+1}^{0}\left\{\left[z_{i}^{0}-d_{i}\left(t, \varepsilon_{i}\right)\right]^{+}\right\} \\
& H_{i}^{0}\left(z_{i}^{0}\right)= \int_{0}^{\tau}\left\{p_{i} e^{\gamma t} \min \left[z_{i}^{0}-d_{i}\left(t, \varepsilon_{i}\right)\right]-w_{i} z_{i}^{0}\right. \\
&\left.-h_{i}\left[z_{i}^{0}-d_{i}\left(t, \varepsilon_{i}\right)\right]^{+}\right\} g_{i}(t) d t
\end{aligned}
$$

Using Bellman's principle of optimality as Li et al. [18] and Chen et al. [19], we can characterize the firm's myopic optimal ordering policies without put option contracts under inflation. Define $w_{n+1}=v$ and $V_{i}^{0+}\left(y_{i}^{0}\right)=V_{i}^{0+}\left(y_{i}^{0}\right)-w_{i} y_{i}^{0}$. Then, the following recursion is equivalent to (1)-(3):

$$
V_{i}^{0+}\left(y_{i}^{0}\right)=\max _{z_{i}^{0} \geq y_{i}^{0}}\left\{J_{i}^{0+}\left(z_{i}^{0}\right)\right\}
$$

where $V_{n+1}^{0+}\left(y_{i}^{0}\right)=0 \quad\left(y_{i}^{0} \geq 0\right)$, and

$$
\begin{aligned}
& J_{i}^{0+}\left(z_{i}^{0}\right)=H_{i}^{0+}\left(z_{i}^{0}\right)+\alpha V_{i+1}^{0+}\left\{\left[z_{i}^{0}-d_{i}\left(t, \varepsilon_{i}\right)\right]^{+}\right\} \\
& H_{i}^{0+}\left(z_{i}^{0}\right)= \int_{0}^{\tau}\left\{p_{i} e^{\gamma t} \min \left[z_{i}^{0}-d_{i}\left(t, \varepsilon_{i}\right)\right]-w_{i} z_{i}^{0}\right. \\
&\left.-\left(h_{i}-\alpha w_{i+1}\right)\left[z_{i}^{0}-d_{i}\left(t, \varepsilon_{i}\right)\right]^{+}\right\} g_{i}(t) d t
\end{aligned}
$$

With some algorithm, we get the following lemma.

Proposition 1 Without put option contracts, the firm's optimal firm order quantity in period $i$ is

$$
Q_{i}^{0^{*}}=\left\{\begin{array}{cl}
s_{i}^{0^{*}}-y_{i}^{0} & \text { if } y_{i}^{0} \leq s_{i}^{0^{*}} \\
0 & \text { if } y_{i}^{0} \geq s_{i}^{0^{*}}
\end{array}\right.
$$

where $s_{i}^{0^{*}}=\max _{z^{0}}\left\{J_{i}^{0}\left(z^{0}\right)\right\}$.

Proof of Proposition 1. This proof of this result has been presented in Wan and Chen [2].

This proposition states that without put option contracts the firm's optimal ordering policy in each period depends on the initial inventory level and the optimal base-stock level $s_{i}^{0^{*}}$ in that period. If $y_{i}^{0} \leq s_{i}^{0^{*}}$, the firm needs to place the firm order before the beginning of period $i$ to raise his inventory level up to $s_{i}^{0^{*}}$. If $y_{i}^{0}>s_{i}^{0^{*}}$, the firm never needs to place the firm order before the beginning of period $i i$.

Denote $s_{i}^{0+}$ as the myopic optimal base-stock level that optimizes the firm's current profit while ignore his future profit. Then we have the following proposition.

Proposition 2 In period $i$, we have

$$
\int_{0}^{\tau}\left(p_{i} e^{\gamma t}+h_{i}-\alpha w_{i+1}\right) \bar{F}_{i}\left[s_{i}^{0+}-x_{i}(t)\right] g(t) d t=w_{i}+h_{i}-\alpha w_{i+1}
$$

Proof of Proposition 2. This proof of this result has been presented in Wan and Chen [2].

Proposition 2 shows that unit wholesale price in period $i+1$ has a positive impact on the myopic optimal base stock level $s_{i}^{0+}$ in period $i$.

\section{Optimal ordering polices with put option contracts}

This section studies the firm's optimal ordering policies with put option contracts under inflation. Before the beginning of period $i$, the firm has a opportunity to place a firm order, denoted as $Q_{i}^{1}$, and meanwhile purchase a certain quantity of put options, denoted as $q_{i}^{1}$. If two types of orders are placed, the inventory level of the firm can be raised from $y_{i}^{1}$ to $z_{i}^{1}$ and part of extra items can be returned though excising put option contracts. If two types of orders are not placed, the inventory level of the firm can be still remained at $y_{i}^{1}$ and only the unsold items in the previous period are used to meet the market demand in that period.

Let $V_{i}^{1}\left(y_{i}^{1}\right)$ be the profit-to-go function with put option contracts from period $i$ to period $n$. Let $k_{i}^{1}=z_{i}^{1}-q_{i}^{1}$. Therefore, determining $\left(z_{i}^{1}, q_{i}^{1}\right)$ is equal to determining $\left(z_{i}^{1}, k_{i}^{1}\right)$. We develop the dynamic formulation as following:

$$
\begin{aligned}
& V_{i}^{1}\left(y_{i}^{1}\right)=w_{i} y_{i}^{1}+\max _{z_{i}^{1} \geq k_{i}^{1} \geq y_{i}^{1}}\left\{J_{i}^{1}\left(z_{i}^{1}, k_{i}^{1}\right)\right\} \\
& \text { where } V_{n+1}^{1}\left(y_{i}^{1}\right)=v y_{i}^{1} \quad\left(y_{i}^{1} \geq 0\right), \text { and } \\
& J_{i}^{1}\left(z_{i}^{1}, k_{i}^{1}\right)= H_{i}^{1}\left(z_{i}^{1}, k_{i}^{1}\right)+\alpha V_{i+1}^{1}\left\{\left[k_{i}^{1}-d_{i}\left(t, \varepsilon_{i}\right)\right]^{+}\right\} \\
& H_{i}^{1}\left(z_{i}^{1}, k_{i}^{1}\right)=\int_{0}^{\tau}\left\{p_{i} e^{\gamma t} \min \left[z_{i}^{1}-d_{i}\left(t, \varepsilon_{i}\right)\right]-w_{i} z_{i}^{1}-o_{i}\left(z_{i}^{1}-k_{i}^{1}\right)\right. \\
&-e_{i} \min \left[\left(z_{i}^{1}-k_{i}^{1}\right),\left(z_{i}^{1}-d_{i}\left(t, \varepsilon_{i}\right)\right)^{+}\right] \\
&\left.-h_{i}\left[k_{i}^{1}-d_{i}\left(t, \varepsilon_{i}\right)\right]^{+}\right\} g(t) d t
\end{aligned}
$$

Define $w_{n+1}=v$ and $V_{i}^{1+}\left(y_{i}^{1}\right)=V_{i}^{1}\left(y_{i}^{1}\right)-w_{i} y_{i}^{1}$. Then, the following recursion is equivalent to (7)-(9):

$$
\begin{aligned}
& V_{i}^{1+}\left(y_{i}^{1}\right)=\max _{z_{i}^{1} \geq k_{i}^{1} \geq y_{i}^{1}}\left\{J_{i}^{1+}\left(z_{i}^{1}, k_{i}^{1}\right)\right\} \\
& \text { where } V_{n+1}^{1+}\left(y^{1}\right)=0 \quad\left(y^{1} \geq 0\right), \text { and } \\
& J_{i}^{1+}\left(z_{i}^{1}, k_{i}^{1}\right)=H_{i}^{1+}\left(z_{i}^{1}, k_{i}^{1}\right)+\alpha V_{i+1}^{1+}\left\{\left[k_{i}^{1}-d_{i}\left(t, \varepsilon_{i}\right)\right]^{+}\right\} \\
& \begin{aligned}
H_{i}^{1+}\left(z_{i}^{1}, k_{i}^{1}\right)=\int_{0}^{\tau}\left\{p_{i} e^{\gamma t} \min \left[z_{i}^{1}-d_{i}\left(t, \varepsilon_{i}\right)\right]-w_{i}\left(z_{i}^{1}-y_{i}^{1}\right)-o_{i}\left(z_{i}^{1}-k_{i}^{1}\right)\right. \\
\quad-e_{i} \min \left[\left(z_{i}^{1}-k_{i}^{1}\right),\left(z_{i}^{1}-d_{i}\left(t, \varepsilon_{i}\right)\right)^{+}\right] \\
\left.\quad-\left(h_{i}-\alpha w_{i+1}\right)\left[k_{i}^{1}-d_{i}\left(t, \varepsilon_{i}\right)\right]^{+}\right\} g_{i}(t) d t
\end{aligned}
\end{aligned}
$$

With some algorithm, we get the following lemma.

Proposition 3 With put option contracts, the firm's optimal firm order quantity in period $i$ is

$$
Q_{i}^{1^{*}}=\left\{\begin{array}{cl}
s_{i}^{1^{*}}-y_{i}^{1} & \text { if } y_{i}^{1} \leq S_{i}^{1^{*}} \\
0 & \text { if } y_{i}^{1} \geq S_{i}^{1^{*}}
\end{array}\right.
$$

and the firm's optimal put order quantity in period $i$ is

$$
\begin{aligned}
& q_{i}^{1^{*}}=\left\{\begin{array}{cc}
S_{i}^{1^{*}}-s_{i}^{1^{*}} & \text { if } y_{i}^{1} \leq s_{i}^{1^{*}} \\
S_{i}^{1^{*}}-y_{i}^{1} & \text { if } s_{i}^{1^{*}} \leq y_{i}^{1} \leq S_{i}^{1^{*}} \\
0 & \text { if } y_{i}^{1}>S_{i}^{1^{*}}
\end{array}\right. \\
& \text { where } \\
& S_{i}^{1^{*}}=\max _{z_{i}^{1}}\left\{J_{i}^{1+}\left(z_{i}^{1}, k_{i}^{1}\right)\right\}
\end{aligned}
$$

and 


$$
s_{i}^{1^{*}}=\max _{k_{i}^{1}}\left\{J_{i}^{1+}\left(z_{i}^{1}, k_{i}^{1}\right)\right\} .
$$

Proof of Proposition 3. Similar with Wan and Chen [2], we can prove that with put option contracts the optimal solution $z_{i}^{1^{*}}$ is $z_{i}^{1^{* *}}=\left\{\begin{array}{cll}S_{i}^{1^{* *}}-y_{i}^{1} & \text { if } y_{i}^{1} \leq S_{i}^{1^{* *}} \\ 0 & \text { if } & y_{i}^{1} \geq S_{i}^{1^{*}}\end{array}\right.$ and the optimal solution $k_{i}^{1^{*}}$ is $k_{i}^{1^{*}}=\left\{\begin{array}{cll}s_{i}^{1^{*}}-y_{i}^{1} & \text { if } y_{i}^{1} \leq s_{i}^{1^{*}} \\ 0 & \text { if } y_{i}^{1} \geq s_{i}^{1^{*}}\end{array}\right.$. Thus, the above results can be derived.

This proposition states that with put option contracts the firm's optimal ordering policy in each period depends on the initial inventory level and two optimal base-stock levels $S_{i}^{1^{*}}$ and $s_{i}^{1^{*}}$ in that period. If $y_{i}^{1} \leq s_{i}^{1^{*}}$, the firm needs to place the two types of orders before the beginning of period $i$ to raise his highest inventory level up to $S_{i}^{1^{*}}$ and maintain the lowest the inventory level up to $s_{i}^{1^{*}}$. If $s_{i}^{1^{*}} \leq y_{i}^{1} \leq S_{i}^{1^{*}}$, the firm needs to place the two types of orders before the beginning of period $i$ to raise his highest inventory level up to $S_{i}^{1^{*}}$ and maintain the lowest the inventory level up to $y_{i}^{1}$. If $y_{i}^{1}>S_{i}^{1^{*}}$, the firm never needs to place any type of orders before the beginning of period $i i$.

Denote $s_{i}^{1+}$ and $S_{i}^{1+}$ as the myopic optimal base-stock levels that optimize the firm's current profit while ignore his future profit. Then we have the following proposition.

Proposition 4 In period $i$, we have

$$
\begin{aligned}
\int_{0}^{\tau}\left(p_{i} e^{\gamma t}-e_{i}\right) \bar{F}_{i}\left[S_{i}^{1+}-x_{i}(t)\right] g(t) d t & =w_{i}+o_{i}-e_{i} \\
\text { and } & \\
\int_{0}^{\tau}\left(e_{i}+h_{i}-\alpha w_{i+1}\right) \bar{F}_{i}\left[s_{i}^{1+}-x_{i}(t)\right] g(t) d t & =o_{i}
\end{aligned}
$$

Proof of Proposition 4. From (18), we can derive $H_{i}^{1+}\left(z_{i}^{1}, k_{i}^{1}\right)$ is concave in $\left(z_{i}^{1}, k_{i}^{1}\right)$. Let the first derivative of $H_{i}^{1+}\left(z_{i}^{1}, k_{i}^{1}\right)$ be zero. We can derive the above results.

Proposition 4 shows that unit wholesale price in period $i+1$ has a positive impact on the myopic optimal base stock level $s_{i}^{1+}$ in period $i$ and has no impact on the myopic optimal base stock level $S_{i}^{1+}$ in period $i$.

\section{The impact of put option contracts}

First we explore the impact of put option contracts on the firm's decisions under inflation. With some algorithm, we get the following proposition.

Proposition 5 For all periods, we have

$$
s_{i}^{1+}<s_{i}^{0+}<S_{i}^{1+}
$$

Proof of Proposition 5. From proposition 2 and 4, we have that

$$
\left.\frac{\partial H_{i}^{1+}\left(z_{i}^{1}, k_{i}^{1}\right)}{\partial z_{i}^{1}}\right|_{z_{i}=s_{i}^{0+}}>\int_{0}^{\tau} \frac{p_{i} e^{\gamma t}-e_{i}}{p_{i} e^{\gamma t}+h_{i}-\alpha w_{i+1}}\left\{\left(p_{i} e^{\gamma t}-w_{i}-o_{i}\right)-\left(p_{i} e^{\gamma t}-e_{i}\right) F_{i}\left[s_{i}^{0+}-x_{i}(t)\right]\right\} g_{i}(t) d t=0
$$

Therefore, we have $s_{i}^{0+}<S_{i}^{1+}$. Moreover, we derive that

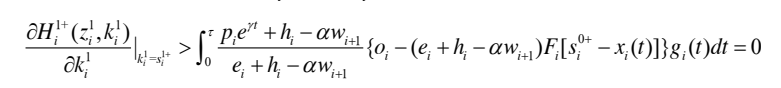

Then, we can derive the above result.

This proposition shows that put option contracts has an important impact on the myopic optimal base-stock levels. Thus, we conclude that the utilization of put option contracts might motivate the firm to increase the firm order in each period under inflation. In addition, the firm's put options order quantity in each period under inflation might be guaranteed to be sufficient enough so as to reduce the revenue loss caused by the increase in the firm order after using put option contracts.

Now we explore the impact of put option contracts on the the firm's performance under inflation. With some algorithm, we get the following proposition.

Proposition 6 The firm's myopic optimal expected profit over the whole selling cycle is higher with put option contract than without it.

Proof of Proposition 6. Without put option contracts, the firm's myopic optimal expected profit in period $i$ is

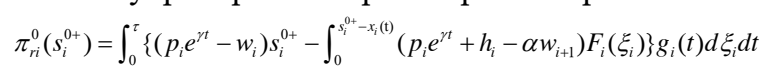

With put option contracts, the firm's myopic optimal expected profit in period $i$ is

$$
\begin{aligned}
& \pi_{r i}^{1}\left(S_{i}^{1+}, s_{i}^{1+}\right)=\int_{0}^{\tau}\left\{\left(p_{i} e^{\gamma t}-w_{i}-o_{i}\right) S_{i}^{l^{++}}-\int_{0}^{S^{1+}-x_{i}(t)}\left(p_{i} e^{\gamma t}-e_{i}\right) F_{i}\left(\xi_{i}\right)\right\} g_{i}(t) d \xi_{i} d t \\
& +\int_{0}^{\tau}\left\{o_{i} S_{i}^{1+}-\int_{0}^{s^{i t}-x_{i}(t)}\left(e_{i}+h_{i}-\alpha w_{i+1}\right) F_{i}\left(\xi_{i}\right)\right\} g_{i}(t) d \xi_{i} d t
\end{aligned}
$$

It is easy to derive that $\pi_{r i}^{1}\left(S_{i}^{1+}, s_{i}^{1+}\right)>\pi_{r i}^{0}\left(s_{i}^{0+}\right)$. Thus, the firm's myopic optimal expected profit over the whole selling cycle is higher with put option contract than without it.

This proposition states that the utilization of put option contracts has an important impact on the firm's myopic optimal expected profit. Therefore, we conclude that the utilization of put option contracts is advantageous for the firm to enhance the incomes under inflation.

\section{NUMERICAL EXAMPLE}

Now we provide a numerical analysis to explore the impact of the contract parameters on the firm's decisions and performance under inflation. The default values of the dataset are as following: $i=2, x_{1}(t)=250_{i} e^{-0.001 t}$,

$x_{1}(t)=150_{i} e^{-0.002 t}, t \sim U(0,100), \varepsilon_{1} \sim U(0,20)$,

$\varepsilon_{2} \sim U(0,40), \gamma=0.003, \alpha=0.8, p_{1}=10, p_{2}=15$,

$w_{1}=4, w_{2}=5.5, o_{1}=0.65, o_{2}=1.25, e_{1}=3.5$,

$e_{2}=5, h_{1}=2, h_{2}=2.8, v=4.5$.

We show the impact of $w_{1}$ on the myopic optimal base-stock levels and the myopic optimal expected profits in Tab. 1.

Tab. 1 The effect of $w_{1}$

\begin{tabular}{l|l|l|l|l|l|l|l|l}
\hline$w_{1}$ & $s_{1}^{1+}$ & $S_{1}^{1+}$ & $s_{2}^{1+}$ & $S_{2}^{1+}$ & $s_{1}^{0+}$ & $s_{2}^{0+}$ & $\Pi_{r}^{1+}$ & $\Pi_{r}^{0+}$ \\
\hline 4.00 & 249.73 & 254.24 & 147.86 & 169.40 & 253.70 & 163.98 & 3310.03 & 3294.91 \\
4.05 & 249.73 & 254.12 & 147.86 & 169.40 & 253.60 & 163.98 & 3297.33 & 3282.23 \\
4.10 & 249.73 & 254.00 & 147.86 & 169.40 & 253.49 & 163.98 & 3284.62 & 3269.55 \\
4.15 & 249.73 & 253.87 & 147.86 & 169.40 & 253.38 & 163.98 & 3271.93 & 3256.88 \\
4.20 & 249.73 & 253.75 & 147.86 & 169.40 & 253.27 & 163.98 & 3259.24 & 3244.22 \\
\hline
\end{tabular}

Table 1 states that the increase in unit wholesale price $w_{1}$ will lead to the following changes: (1) The myopic 
optimal base-stock level $S_{1}^{1+}$ has a tendency to decrease, indicating with put option contracts the firm might reduce both the firm order and the put options order in the first period under inflation. (2) The myopic optimal base-stock level $s_{1}^{0+}$ has a tendency to decrease, indicating without put option contracts the firm might reduce the firm order in the first period under inflation.
(3) The myopic optimal expected profits $\Pi_{r}^{1+}$ and $\Pi_{r}^{0+}$ have a tendency to decrease, indicating with and without put option contracts the firm might obtain less revenue over the whole selling cycle under inflation.

We show the impact of $w_{2}$ on the myopic optimal base-stock levels and the myopic optimal expected profits in Tab. 2.

Tab. 2 The effect of $w_{2}$

\begin{tabular}{l|l|l|l|l|l|l|l|l}
\hline$w_{2}$ & $s_{1}^{1+}$ & $S_{1}^{1+}$ & $s_{2}^{1+}$ & $S_{2}^{1+}$ & $s_{1}^{0+}$ & $s_{2}^{0+}$ & $\Pi_{r}^{1+}$ & $\Pi_{r}^{0+}$ \\
\hline 5.50 & 249.73 & 254.24 & 147.86 & 169.40 & 253.70 & 163.98 & 3310.03 & 3294.91 \\
5.55 & 250.17 & 254.24 & 147.86 & 169.24 & 253.77 & 163.86 & 3303.46 & 3288.66 \\
5.60 & 250.65 & 254.24 & 147.86 & 169.08 & 253.84 & 163.74 & 3296.89 & 3282.41 \\
5.65 & 251.17 & 254.24 & 147.86 & 168.92 & 253.91 & 163.62 & 3290.34 & 3276.16 \\
5.70 & 251.74 & 254.24 & 147.86 & 168.76 & 253.98 & 163.50 & 3283.83 & 3269.93 \\
\hline
\end{tabular}

Table 2 states that the increase in unit wholesale price $w_{2}$ will lead to the following changes: (1) The myopic optimal base-stock level $s_{1}^{1+}$ has a tendency to increase, indicating with put option contracts the firm might reduce the put options order in the first period under inflation. (2) The myopic optimal base-stock level $S_{2}^{1+}$ has a tendency to decrease, indicating with put option contracts the firm might reduce both the firm order and the put options order in the second period under inflation. (3) The myopic optimal base-stock level $s_{1}^{0+}$ has a tendency to increase, indicating without put option contracts the firm might increase the firm order in the first period under inflation. (4) The myopic optimal base-stock level $s_{2}^{0+}$ has a tendency to decrease, indicating without put option contracts the firm might reduce the firm order in the second period under inflation. (5) The myopic optimal expected profits $\Pi_{r}^{1+}$ and $\Pi_{r}^{0+}$ have a tendency to decrease, indicating with and without put option contracts the firm might obtain less revenue over the whole selling cycle under inflation.

We show the impact of $o_{1}$ on the myopic optimal base-stock levels and the myopic optimal expected profits in Tab. 3.

Tab. 3 The effect of $o_{1}$

\begin{tabular}{l|l|l|l|l|l|l|l|l}
\hline$o_{1}$ & $s_{1}^{1+}$ & $S_{1}^{1+}$ & $s_{2}^{1+}$ & $S_{2}^{1+}$ & $s_{1}^{0+}$ & $s_{2}^{0+}$ & $\Pi_{r}^{1+}$ & $\Pi_{r}^{0+}$ \\
\hline 0.65 & 249.73 & 254.24 & 147.86 & 169.40 & 253.70 & 163.98 & 3310.03 & 3294.91 \\
0.70 & 250.63 & 254.12 & 147.86 & 169.40 & 253.70 & 163.98 & 3309.84 & 3294.91 \\
0.75 & 251.54 & 254.00 & 147.86 & 169.40 & 253.70 & 163.98 & 3309.69 & 3294.91 \\
0.80 & 252.45 & 253.87 & 147.86 & 169.40 & 253.70 & 163.98 & 3309.60 & 3294.91 \\
0.85 & 253.36 & 253.75 & 147.86 & 169.40 & 253.70 & 163.98 & 3309.55 & 3294.91 \\
\hline
\end{tabular}

Table 3 states that the increase in unit purchase price of put option $o_{1}$ will lead to the following changes: (1) The myopic optimal base-stock level $S_{1}^{1+}$ has a tendency to decrease, indicating with put option contracts the firm might reduce the firm order in the first period under inflation. (2) The myopic optimal base-stock level $s_{1}^{1+}$ has a tendency to increase, indicating with put option contracts the firm might reduce the put options order in the first period under inflation. (3) The myopic optimal expected profits $\Pi_{r}^{1+}$ has a tendency to decrease, indicating with put option contracts the firm might obtain less revenue over the whole selling cycle.

We show the impact of $o_{2}$ on the myopic optimal base-stock levels and the myopic optimal expected profits in Tab. 4.

Tab. 4 The effect of $o_{2}$

\begin{tabular}{l|l|l|l|l|l|l|l|l}
\hline$o_{2}$ & $s_{1}^{1+}$ & $S_{1}^{1+}$ & $s_{2}^{1+}$ & $S_{2}^{1+}$ & $s_{1}^{0+}$ & $s_{2}^{0+}$ & $\Pi_{r}^{1+}$ & $\Pi_{r}^{0+}$ \\
\hline 1.25 & 249.73 & 254.24 & 147.86 & 169.40 & 253.70 & 163.98 & 3310.03 & 3294.91 \\
1.30 & 249.73 & 254.24 & 148.33 & 169.24 & 253.70 & 163.98 & 3309.15 & 3294.91
\end{tabular}




\begin{tabular}{l|l|l|l|l|l|l|l|l}
1.35 & 249.73 & 254.24 & 148.81 & 169.08 & 253.70 & 163.98 & 3308.32 & 3294.91 \\
1.40 & 249.73 & 254.24 & 149.29 & 168.92 & 253.70 & 163.98 & 3307.52 & 3294.91 \\
1.45 & 249.73 & 254.24 & 149.76 & 168.76 & 253.70 & 163.98 & 3306.75 & 3294.91 \\
\hline
\end{tabular}

Table 4 states that the increase in unit purchase price of put option $\mathrm{O}_{2}$ will lead to the following changes: (1) The myopic optimal base-stock level $S_{2}^{1+}$ has a tendency to decrease, indicating with put option contracts the firm might reduce the firm order in the second period under inflation. (2) The myopic optimal base-stock level $s_{2}^{1+}$ has a tendency to increase, indicating with put option contracts the firm might reduce the put options

Tab.5 The effect of $e_{1}$

\begin{tabular}{l|l|l|l|l|l|l|l|l}
\hline$e_{1}$ & $s_{1}^{1+}$ & $S_{1}^{1+}$ & $s_{2}^{1+}$ & $S_{2}^{1+}$ & $s_{1}^{0+}$ & $s_{2}^{0+}$ & $\Pi_{r}^{1+}$ & $\Pi_{r}^{0+}$ \\
\hline 3.50 & 249.73 & 254.24 & 147.86 & 169.40 & 253.70 & 163.98 & 3310.03 & 3294.91 \\
3.55 & 249.21 & 254.34 & 147.86 & 169.40 & 253.70 & 163.98 & 3310.21 & 3294.91 \\
3.60 & 248.74 & 254.44 & 147.86 & 169.40 & 253.70 & 163.98 & 3310.40 & 3294.91 \\
3.65 & 248.31 & 254.55 & 147.86 & 169.40 & 253.70 & 163.98 & 3310.60 & 3294.91 \\
3.70 & 247.91 & 254.65 & 147.86 & 169.40 & 253.70 & 163.98 & 3310.82 & 3294.91 \\
\hline
\end{tabular}

Table 5 states that the increase in unit exercise price of put option $e_{1}$ will lead to the following changes: (1) The myopic optimal base-stock level $S_{1}^{1+}$ has a tendency to increase, indicating with put option contracts the firm might increase the firm order in the first period under inflation. (2) The myopic optimal base-stock level $s_{1}^{1+}$ has a tendency to decrease, indicating with put option contracts the firm might increase the put options inflation. profits in Tab. 6. order in the second period under inflation. (3) The myopic optimal expected profits $\Pi_{r}^{1+}$ has a tendency to decrease, indicating with put option contracts the firm might obtain less revenue over the whole selling cycle.

We show the impact of $e_{1}$ on the myopic optimal base-stock levels and the myopic optimal expected profits in Tab. 5.

order in the first period under inflation. (3) The myopic optimal expected profits $\Pi_{r}^{1+}$ has a tendency to increase, indicating with put option contracts the firm might obtain more revenue over the whole selling cycle under

We show the impact of $e_{2}$ on the myopic optimal base-stock levels and the myopic optimal expected

Tab. 6 The effect of $e_{2}$

\begin{tabular}{l|l|l|l|l|l|l|l|l}
\hline$e_{2}$ & $s_{1}^{1+}$ & $S_{1}^{1+}$ & $s_{2}^{1+}$ & $S_{2}^{1+}$ & $s_{1}^{0+}$ & $s_{2}^{0+}$ & $\Pi_{r}^{1+}$ & $\Pi_{r}^{0+}$ \\
\hline 5.00 & 249.73 & 254.24 & 147.86 & 169.40 & 253.70 & 163.98 & 3310.03 & 3294.91 \\
5.05 & 249.73 & 254.24 & 147.72 & 169.53 & 253.70 & 163.98 & 3310.48 & 3294.91 \\
5.10 & 249.73 & 254.24 & 147.58 & 169.67 & 253.70 & 163.98 & 3310.99 & 3294.91 \\
5.15 & 249.73 & 254.24 & 147.45 & 169.81 & 253.70 & 163.98 & 3311.49 & 3294.91 \\
5.20 & 249.73 & 254.24 & 147.32 & 169.94 & 253.70 & 163.98 & 3312.00 & 3294.91 \\
\hline
\end{tabular}

Table 6 states that the increase in unit exercise price of put option $e_{2}$ will lead to the following change: (1) The myopic optimal base-stock level $S_{2}^{1+}$ has a tendency to increase, indicating with put option contracts the firm might increase the firm order in the second period under inflation. (2) The myopic base-stock level $s_{2}^{1+}$ has a tendency to decrease, indicating with put option contracts the firm might increase the put options order in the second period under inflation. (3) The myopic optimal expected profits $\Pi_{r}^{1+}$ has a tendency to increase, indicating with put option contracts the firm might obtain more revenue over the whole selling cycle under inflation.

\section{Conclusions}

This paper studies the phenomenon characterized by the rising price and the shrinking demand caused by inflation. We take into account the firm's multiperiod ordering problem. To manage the risks of price and demand caused by inflation, the firm has an opportunity to place two types of orders, including the firm order and the put options order, before the beginning of each period. To the best of our knowledge, this is the first paper relating to the impact of put option contracts on the firm's multiperiod decisions and performance under inflation.

This paper can be extended in the following several directions. (1)In this paper, the retail price is assumed to 
be irrelevant with the market demand in each period. We plan to consider an extended multiperiod ordering model with price dependent demand. (2) In this paper, we only considering the decisions of one firm. We plan to discuss the decisions of the supply chain with various power structures. (3) In this paper, the firm is assumed to be risk-neutral. An extension of our model is to consider his risk preference.

\section{Acknowledgment}

The authors are supported by National Natural Science Foundation of China (71802168), Humanities and Social Science Foundation of Ministry of Education of China (18YJC630165).

\section{References}

1. Fu, Q., Lee, C. Y., Teo, C. P. 2010. "Procurement management using option contracts: random spot price and the portfolio effect." IIE Transactions 42 (11): 793-811.

2. Wan, N., Chen, X. 2016. "Multiperiodic procurement problem with option contracts under inflation." Mathematical Problems in Engineering 1: $1-11$.

3. Tripathi, R. P., Singh, D., Mishra, T. 2014. "EOQ model for deteriorating items with exponential time dependent demand rate under inflation when supplier credit linked to order quantity." International Journal of Supply and Operations Management 1 (1): 20-37.

4. Khurana, D. 2015. "Two warehouse inventory model for deteriorating items with time dependent demand under inflation." International Journal of Computer Applications 114 (7):34-38.

5. Das, D., Kar, M. B., Roy, A., Kar, S. 2012. "Two-warehouse production model for deteriorating inventory items with stock-dependent demand under inflation over a random planning horizon." Central European Journal of Operations Research 20 (2): 251-280.

6. Bhunia, A. K., Shaikh, A. A., Gupta, R. K. 2015. “A study on two-warehouse partially backlogged deteriorating inventory models under inflation via particle swarm optimisation." International Journal of Systems Science, 46(6): 1036-1050.

7. Xue, W., Ma, L., Shen, H. 2015. "Optimal inventory and hedging decisions with CVaR consideration." International Journal of Production Economics 162: 70-82.

8. Wang, C., Chen, X. 2018. "Joint order and pricing decisions for fresh produce with put option contracts." Journal of the Operational Research Society, 69(3): 474-484.

9. Basu, P., Liu, Q., Stallaert, J. 2019. "Supply chain management using put option contracts with information asymmetry." International Journal of Production Research, 57(6): 1772-1796.
10. Wan, N., Chen, X. 2019. "The role of put option contracts in supply chain management under inflation." International Transactions in Operational Research, 26(4): 1451-1474.

11. Hu, Z., Tian, J., Feng, G. 2019. "A relief supplies purchasing model based on a put option contract." Computers \& Industrial Engineering, 127: 253-262.

12. Lu, Y., Song, M., Yang, Y. 2016. "Joint inventory and pricing coordination with incomplete demand information." Production and operations management, 25(4), 701-718.

13. Feinberg, E. A., Liang, Y. 2017. "Structure of optimal policies to periodic-review inventory models with convex costs and backorders for all values of discount factors." Annals of Operations Research, DOI: $10.1007 / \mathrm{s} 10479-017-2548-6$

14. Song, H., Ran, L., Shang, J. 2017. "Multi-period optimization with loss-averse customer behavior: Joint pricing and inventory decisions with stochastic demand." Expert Systems with Applications, 72, 421-429.

15. Benjaafar, S., Chen, D., Yu, Y. 2018. "Optimal policies for inventory systems with concave ordering costs." Naval Research Logistics (NRL), 65(4): 291-302.

16. Jaggi, C. K., Khanna, A. 2009 "Retailer's ordering policy for deteriorating items with inflation-induced demand under trade credit policy." International Journal of Operational Research 6 (3): 360-379.

17. Xiao, T., Jin, J., Chen, G., Shi, J., Xie, M. 2010. "Ordering, wholesale pricing and lead-time decisions in a three-stage supply chain under demand uncertainty." Computers \& Industrial Engineering 59 (4): 840-852.

18. Li, X., Li, Y., Cai, X. 2011. "On a multi-period supply chain system with supplementary order opportunity." European Journal of Operational Research 209 (3): 273-284.

19. Chen, Y. F., Lu, Y., Xu, M. 2012. “Optimal inventory control policy for periodic-review inventory systems with inventory-level-dependent demand." Naval Research Logistics 59 (6): 430-440. 